\title{
Examination of a Peer-Led, Non-Diet Nutrition and Exercise Adherence Pilot Program on a College Campus: FitU
}

\author{
Linda A. Keeler ${ }^{1}$, Dawn E. Clifford ${ }^{2}$, Buck August ${ }^{2}$, Petra Kowalski ${ }^{2}$, and Michelle Neyman \\ Morris $^{2}$ \\ ${ }^{1}$ Western Washington University \\ ${ }^{2}$ California State University, Chico
}

\begin{abstract}
A non-equivalent control group design was utilized to investigate the effect of a non-diet, peer-led, tailored nutrition and exercise adherence intervention (FitU) on exercise stages of change, intuitive eating, and barriers to healthy eating and exercise in college females. Female students $(n=17)$ who enrolled in the 8-10 week program served as the intervention group and general education students who did not receive an intervention served as the control group $(n=16)$. Surveys were administered pre and post intervention over two consecutive semesters. Utilizing ANCOVA analyses, reported barriers to eating healthy decreased $(p=.008)$ and one intuitive eating subscale, eating for physical rather than emotional reasons improved significantly $(p=.01)$ in the intervention group compared to control from pre to post. Further, $65 \%$ of the intervention group reported an improvement in exercise stage of change and none relapsed compared with only $20 \%$ improvement and $40 \%$ relapse in the control group from pre to postintervention. The majority of the intervention participants also reported improved dietary (82.4\%) and exercise $(76.5 \%)$ patterns/thoughts. Peer-led and individually tailored, non-diet nutrition and exercise interventions may effectively promote healthy behaviors among college females.
\end{abstract}

(c) 2013 Californian Journal of Health Promotion. All rights reserved.

Keywords: non-diet, exercise, nutrition, physical activity, peer counseling

\section{Introduction}

\section{Examination of a Peer-Led, Non-Diet Nutrition and Exercise Adherence Pilot Program on a College Campus: FitU}

As new college students move away from home and begin independent living, they are faced with the task of regulating their own health behaviors from physical activity to dietary patterns. College students often lack the skills needed for basic meal planning (Larson, Perry, Story, Neumark-Sztainer, 2006) and often report diets low in fruits and vegetables and high in dietary fat (American College Health Association, 2011; Lowry et al, 2000). Concurrently, it has been estimated that 36\%$50 \%$ of college students are sedentary and $50 \%$ fail to meet the American College of Sports Medicine standards for physical activity (Keating, Guan, Pinero, \& Bridges, 2005).
Physical activity levels decrease throughout adolescence with the steepest decline between the ages of 15 and 25 years, and over $80 \%$ of those who are inactive in college will continue their sedentary lifestyle later in life (Keating et al., 2005). Thus, health patterns established while attending universities are of significant importance and there is a need for development of nutrition and physical activity programming.

\section{Weight Loss Interventions}

Poor dietary and inactivity patterns in college often result in weight gain (e.g., Cluskey \& Grobe, 2009) and many attempted diet restrictions as solutions. Unfortunately, traditional dietary interventions aimed at weight loss are often ineffective in the long term and may be physiologically and psychologically damaging (Bacon et al., 2002; Bacon, Stern, Van Loan, \& Keim, 2005; Bacon \& Aphramor, 2011; 
Mann et al., 2007), especially in young adult females (Ackard, Croll, \& Kearney-Cooke, 2002). Further, regardless of the diet method used, any weight lost is typically regained over time (Mann et al., 2007; Neumark-Sztainer et al., 2006). Weight cycling, which often results from restrictive dieting patterns, can also lead to negative psychological and physiological health outcomes (Bacon \& Aphramor, 2011, Mann et al., 2007). Further, participants actually prefer programs that promote lifestyle changes instead of caloric restriction and weight loss (Thomas, Lewis, Hyde, Castle, \& Komesaroff, 2010), suggesting a need for alternative approaches to health programming.

Emerging evidence supports that programming influenced by an alternative non-diet, or Health at Every Size ${ }^{\circledR 1}\left(\mathrm{HAES}^{\circledR}\right)$ paradigm may be more effective at promoting long-term dietary and physical activity behavior change than traditional diet approaches (Bacon \& Aphramor, 2011; Bacon et al., 2002; Bacon et al., 2005; Provencher et al., 2009; Robinson, Putnam \& McKibbin, 2007; Steinhardt et al., 1999). HAES approaches promote healthful behaviors and improved fitness regardless of weight status, and focus on eating in response to internal hunger and fullness cues (intuitive eating) and incorporating self-determined, enjoyable physical activity (Bacon et al., 2005). Intrinsic motivation to change is fostered in HAES programs, whereas extrinsic motivation is often the focus of diet programs. Even though intrinsic motivation is the focus in HAES programs, several improved health outcomes have been observed long term (e.g., total cholesterol, lowdensity lipoprotein, systolic blood pressure) compared to traditional diet programs (Bacon et al., 2005). Continued exploration of different structures of HAES programming is needed as it expands to various populations.

\section{Nutrition and Physical Activity Counseling} The transtheoretical model of behavior change approach. Individual counseling for nutrition and physical activity is one type of health programming that can result in positive

\footnotetext{
${ }^{1}$ Health at Every Size is a registered trademark of the Association for Size Diversity and Health and used with permission.
}

health behavior changes (Proper, Hildenbrandt, Van der Beek, Twisk, \& Van Mechelen, 2003). There is strong evidence that individual counseling-based interventions that utilize the transtheoretical model of behavior change (TTM; Prochaska \& DiClemente, 1983) are effective in increasing physical activity (Kahn et al., 2002; Marcus \& Forsyth, 2009; Marcus, Rossi, Selby, Niaura, \& Abrams, 1992), increasing fruit and vegetable intake (Elliot et al., 2007; Stevens, Glasgow, Toobert, Karanja, \& Smith, 2003), and decreasing total dietary fat, saturated fat and serum LDL (Burke, DunbarJacob, Orchard, \& Sereika, 2005). The TTM categorizes individuals according to "readiness" to change a health behavior from precontemplation (not contemplating change) to maintenance (regularly engaging in healthy behavior change for more than six months), and health messages are adjusted or "tailored" based on the client's stage of change for a given behavior (Prochaska, DiClemente, Velicer, \& Rossi, 1993). HAES programming can be tailored to a person based on the transtheoretical model within individual counseling sessions.

Nutrition and physical activity messengers. Tailored behavior change counseling may be most effective when provided by an individual trained in a specific field of study. Nutrition counseling is often performed by Registered Dietitians or others trained in health or wellness coaching who may or may not be trained in a HAES approach. Physical activity counseling is a common specialty within the field of sport and exercise psychology, which has the aim of helping individuals or groups adopt, increase and/or maintain physical activity. Physical activity counseling can focus on helping someone adhere to a self-determined physical activity plan or comply with prescribed exercise programs. Counseling for adherence (defined in the present study as exercise adherence counseling) promotes intrinsic motivation for self-determined physical activity as endorsed in the HAES paradigm, yet includes teaching vital behavior change techniques such as: identifying and overcoming barriers, cognitive reframing, time management, social support, goal-setting and relapse prevention (Kahn et al., 2002). To date, there has been no known empirically tested 
intervention that has combined those trained specifically in nutrition and exercise adherence counseling in a program that is based on the HAES paradigm.

In addition to tailored, counseling-based interventions, peer-led interventions are common practice in health education (Colby \& Haldeman, 2007; Elliot et al., 2007; Story, Lytle, Birnbaum, \& Perry, 2002). Individuals are more likely to change their attitudes and behaviors if they believe the messenger is similar to them (Mellanby, Rees, \& Tripp, 2000). Peer education has been effective in promoting behavior change related to both diet (Kunkel, Bell, \& Luccia, 2001; Perez-Escamilla, Hromi-Fiedler, VegaLopez, Bermudez-Millan, \& Segura-Perez, 2008) and physical activity (Elbel, Aldana, Bloswick, \& Lyon, 2003; Sallis et al., 1999). However, there is no known empirically tested intervention that has combined peer mentors specifically trained in HAES concepts such as intuitive eating and exercise adherence counseling. Exercise adherence counseling combined with an intuitive eating approach to nutrition may lead to more effective behavior change than traditional weight loss approaches among young adults. Few interventions have been designed on college campuses that address both nutrition and physical activity (Ferrara, 2009) and no known studies have examined the effectiveness of a peer-led and individually tailored HAES program in a university setting.

\section{The Present Study}

As a result of the lack of university-based HAES programming, a peer-led, interdisciplinary, tailored, HAES intervention, FitU, was created and made available to students on a mid-size campus. The FitU program included four nutrition and three exercise adherence appointments alternating over an academic semester. Sessions were consistent with a HAES approach. Nutrition sessions focused on eating a variety of foods, planning regular meals and snacks, listening to internal cues of hunger and satiety and enjoying food. Exercise adherence sessions focused on increasing awareness of intrinsic benefits of exercise and use of cognitive reframing, behavior modification and self- regulating skills to overcome barriers to increased participation. Thus, the purpose of this investigation was to examine the preliminary effectiveness of such a program on a selection of eating (intuitive eating, barriers to eating healthy, dietary quality), exercise (exercise stage of change, exercise self-efficacy, thoughts/barriers to physical activity), and body image (body weight satisfaction, negative thoughts related to food and/or body) factors.

\section{Methods}

\section{Participants and Recruitment}

Institutional Review Board (IRB) approval for use of human subjects for the current study was granted and all participants provided informed consent prior to data collection. A nonequivalent control group design within an applied setting was utilized in the study. Participants in the intervention group were a self-selected convenience group of full-time university students who enrolled in FitU, which was primarily marketed through electronic campus announcements. Intervention participants were screened using the Physical Activity Readiness Questionnaire (PAR-Q) and limited to students who were not pregnant and free of any major medical illnesses unless cleared by a physician. Subjects paid a $\$ 50$ enrollment fee and received $\$ 25$ back upon completion of the program. See Figure 1 for the organization of the intervention.

A total of 29 (27 women, two men) enrolled in the FitU program, with 24 (22 women) classified as completing a version of the program, four classified as dropouts (three women; attrition rate of $17.24 \%$ ) and one as incomplete (did not complete post assessment). Males were excluded from the present study to control for gender differences, as were five women who received less than the full intervention protocol due to scheduling issues. Consequently, 17 women who completed the full protocol (at least four nutrition and three exercise adherence sessions) were included in the present study. A control group $(\mathrm{n}=16)$ consisted of a convenience sample of full-time, female students in a general education class recruited through classroom 
visits.

\section{Instruments}

Intuitive eating was assessed via the previously validated Intuitive Eating Scale (IES; Tylka, 2006), which consists of 21, five-point Likert scale questions. Within the survey there are three subscales: unconditional permission to eat (11 items), eating for physical rather than emotional reasons (eight items), and reliance on hunger/satiety cues (six items). Respondents are asked to indicate their attitudes or behaviors towards each statement on a 5-point Likert scale from strongly disagree to strongly agree. Example of items include "If I am craving a certain food, I allow myself to have it" (unconditional permission to eat), "I find myself eating when I'm bored even when I'm not physically hungry" (eating for physical rather than emotional reasons), and "I stop eating when I feel full (not overstuffed)" (reliance on hunger/satiety cues).

The one-item Stage of Change for Exercise Ladder (SOC-Ex; Marcus \& Forsyth, 2009) was used to categorize respondents into precontemplation (not exercising), contemplation (not exercising but considering starting), preparation (exercising irregularly), action (exercising regularly for less than six months), or maintenance (regularly exercising for more than six months) stages. A SOC-Ex scale has commonly been used to assess intervention effectiveness (e.g., Marcus, Banspach et al., 1992; Marcus et al., 1998). The Physical Activity Self-Efficacy Scale (SEQ) was used to assess confidence in overcoming common barriers to exercise including such elements as lack of time and vacation (Marcus, Selby, Niara, \& Rossi, 1992). With the SEQ, participants are asked to rate their confidence on maintaining exercise patterns on five different situations (e.g., "When I am in a bad mood") on a 5-point Likert scale from not at all confident to extremely confident. In the present study, individual scores are totaled for analysis. Exercise thoughts and barriers were measured with a 19-item list that combined items from a previous validated scale (Exercise Thoughts Questionnaire; Kendzierski \& Johnson, 1993) and known common barriers and predictors to exercise (Castro, Sallis, Hickmann, Lee \& Chen, 1999) that were potential relevant to this population based on the previous consulting experience. Respondents were asked to indicate how often an item interferes or prevents them from exercising on a 5-point Likert scale from never to very often. Examples of items included "I'd rather socialize" and "School work is more important". Aggregate scores of items were used for analyses.

Perceived barriers to healthy eating were assessed through an 11-item checklist created for this project similar to previous studies (e.g., Clifford \& Keeler, 2009; Silliman, RodasFortier, \& Neyman, 2004). Examples of barriers were "lack of money to purchase healthy foods" and "feelings such as stress, boredom, or sadness". Participants were asked to check all that apply and the number of barriers reported were totaled for analyses. Body weight satisfaction was assessed by the question, "How satisfied are you with your current body weight?" and measured with a 5-point Likert scale ranging from very satisfied to very dissatisfied. Frequency of negative thoughts about food and/or ones' body was assessed via one question with five potential responses ranging from almost always (76-100\% of the day) to never. At the conclusion of the study, a feedback questionnaire was administered to the intervention group to evaluate program satisfaction (5-point scale: not at all satisfied to very satisfied), perceived changes in dietary patterns/thoughts (3-point scale: they are the same, they have improved, they are worse), and rating of the participants' experience with the program staff (5-point scale: excellent to very poor).

\section{FitU Program}

Peer mentors. Upperclass undergraduate and graduate students in nutrition and kinesiology were recruited and trained as peer mentors via specific training and coursework in either nutrition counseling using a HAES approach (e.g. Nutrition Counseling and Education) or exercise science and psychology (e.g., Sport and Exercise Psychology, Exercise Physiology, Exercise Psychology). Six nutrition mentors 
(five females, one male) and seven exercise adherence mentors (five females, two males) participated over one or two semesters on a volunteer basis or received internship course credit for their work with clients. Mentors were supervised in weekly team meetings and with one direct observation by use of a one-way mirror.

Intervention and incentives. The average length of the intervention was 8.3 weeks. Initial sessions averaged 60 minutes with follow-up appointments ranging from 30 to 60 minutes based on client needs. Various interactive client handouts (e.g., exercise goal-setting, meal planning) were created for use by mentors (note: due to the tailored nature of the program, not all clients received the same handouts/interventions; however, handouts allowed for some consistency across clients receiving the same intervention). Program milestone incentives were given including a tshirt, a cookbook and water bottle.

\section{Data Analysis}

Data were analyzed using SPSS version 17.0 software. Eight, one-way between group analyses of covariance (ANCOVA) were computed to determine differences in the dependent variables at post-test (Total IES and subscales, barriers to healthy eating, body weight satisfaction, SEQ, exercise thoughts and barriers) between the intervention and control groups while controlling for baseline scores. Preliminary checks were completed and no violations were found in assumptions for normality, linearity and homogeneity of variance and regression slopes for each ANCOVA. A crosstabs analysis was used to examine stages of change for exercise as assumptions were not met in individual cell size to utilize chi-square analysis.

\section{Results}

Baseline demographics can be found in Table 1 and Cronbach alphas coefficients for multi-item scales can be found in Table 2. All scales had good internal consistency (i.e., larger than .7; Oppenheim, 1992) except the barriers to eating better checklist. It is not believed that the reliability of this analysis has been compromised as this scale is a checklist of a variety of barriers known to be a hindrance to healthy eating and the aim of the intervention was to decrease the number of items checked as barriers. Overall, after adjusting for baseline scores, scores did not differ between the intervention and control group at post testing for total intuitive eating $\mathrm{F}(1,30)=3.021, p=.092, \eta_{p}{ }^{2}=.091$, power $=$ .391 , unconditional permission to eat subscale $\mathrm{F}(1,30)=.004, p=.951, \eta_{p}^{2}=.000$, power $=$ .05 , and reliance on internal hunger/satiety cues subscale $\mathrm{F}(1,30)=3.195, p=.084, \eta_{p}{ }^{2}=.096$, power $=.41$. There was a mean difference at post-test on the eating for physical rather than emotional reasons subscale $\mathrm{F}(1,30)=7.496, p=$ $.01, \eta_{p}{ }^{2}=.20$, power $=.76$, with the intervention group reporting higher scores than the control group. Means and standard deviations of intuitive eating scores can be found in Table 2.

More than $50 \%$ of each group reported the following barriers to eating healthy: lack of time to prepare healthy foods $(75.8 \%$ of entire sample), emotional coping (63.6\%), knowledge of preparing healthy foods $(57.6 \%)$, lack of money for healthy foods $(57.6 \%)$ and easy access to unhealthy foods (57.6\%). Compared to the control group, the intervention group reported significantly fewer total barriers to eating healthy at the end of the program after adjusting for number of barriers reported at baseline. Mean differences F $(1,30)=7.975, p=$ $.008, \eta_{p}{ }^{2}=.210$, power $=.78$ in the number of reported barriers to eating healthy were found at conclusion with the intervention group reporting fewer barriers compared to the control (see Table 2 for means and standard deviations).

The largest percentage of individuals for both groups at both times was classified in the preparation stage of change for exercise (see Table 3). Overall, 65\% (11) of the intervention group reported an improvement in their stage of change and 35\% (six) reported staying in the same stage compared with only $20 \%$ (three) improving, $40 \%$ (six) staying the same and $40 \%$ (six) relapsing (e.g., a negative movement from maintenance to preparation) in the control group 
Table 1

Baseline Demographic Characteristics for Study Participants $(\mathbf{n}=33)$

\begin{tabular}{|c|c|c|}
\hline & Intervention $(n=17)$ & Control $(n=16)$ \\
\hline Mean Age (SD) & $25.53(10.87)$ & $19.63(1.36)$ \\
\hline \multicolumn{3}{|l|}{ Class Standing } \\
\hline Senior & $8(47.1 \%)$ & $1(6.3 \%)$ \\
\hline Junior & $7(41.2 \%)$ & $7(43.8 \%)$ \\
\hline Sophomore & $2(11.8 \%)$ & $4(25.0 \%)$ \\
\hline First Years & - & $4(25.0 \%)$ \\
\hline \multicolumn{3}{|l|}{ Ethnicity } \\
\hline Caucasian & $14(82.4 \%)$ & $15(93.8 \%)$ \\
\hline African-American & $2(11.8 \%)$ & $1(6.3 \%)$ \\
\hline Multi-Racial & $1(5.9 \%)$ & - \\
\hline Off-Campus Housing & $16(94.1 \%)$ & $13(81.3 \%)$ \\
\hline
\end{tabular}

Note. Missing required cell data prevented chi-square analysis for remaining variables.

Note. The intervention group was significantly older than the control group $(p=.04)$

from baseline to post-intervention.

Statistical significance was not observed in additional ANCOVA analyses including physical activity self-efficacy $\mathrm{F}(1,30)=.351$, exercise thoughts and barriers $\mathrm{F}(1,29)=1.307, p$ $=.262$, body weight satisfaction $\mathrm{F}(1,30)=.043$, $p=.837$, and negative thoughts related to food and/or body $\mathrm{F}(1,29)=.2 .075, p=.160$ (see Table 2 for means and standard deviations).

At post-testing, a majority of the intervention participants who completed the program reported that their dietary patterns/thoughts (14, $82.4 \%)$ and exercise patterns/thoughts (13, $76.5 \%$ ) had improved. All other participants reported that their thoughts and patterns had stayed the same. Overall experience with nutrition mentors and exercise adherence mentors were reported to have been excellent or good by $88.2 \% \quad(15)$ and $76.5 \% \quad$ (13), respectively.

\section{Discussion}

This was one of the first known examinations of the effects of a peer-led, individually tailored, nutrition and exercise adherence intervention (FitU) among female students on psychosocial measures of physical activity and nutrition. This program was also unique in that mentors were trained to follow the HAES paradigm with their clients. Although total intuitive eating scores for the FitU participants and control group did not differ significantly from the control group at the end of the intervention, it appears that the intervention had a positive influence on the IES 
Keeler, L.A., Clifford, D.E., August, B., Kowalski, P., Morris, M.N./ Californian Journal of Health Promotion 2013, Volume XX, Issue XX,

Table 2

Means and Standard Deviations for Nutrition and Exercise Variables

\begin{tabular}{|c|c|c|}
\hline Variable & Intervention $(n=17)$ & Control $(n=16)$ \\
\hline & Mean (SD) & Mean (SD) \\
\hline \multicolumn{3}{|l|}{ IES Total $(\alpha=.75)$} \\
\hline Pre & $3.00(0.45)$ & $3.20(0.40)$ \\
\hline Post & $3.42(0.55)$ & $3.27(0.51)$ \\
\hline \multicolumn{3}{|c|}{ IES: Unconditional Permission $(\alpha=.74)$} \\
\hline Pre & $3.08(0.59)$ & $3.03(0.60)$ \\
\hline Post & $3.26(0.81)$ & $3.23(0.67)$ \\
\hline \multicolumn{3}{|c|}{ IES: Eating for Physical Reasons ${ }^{\mathrm{a}}(\alpha=.79)$} \\
\hline Pre & $2.67(0.70)$ & $3.20(0.64)$ \\
\hline Post & $3.19(0.70)$ & $2.98(0.63)$ \\
\hline \multicolumn{3}{|c|}{ IES: Reliance on Hunger/Satiety $(\alpha=.73)$} \\
\hline Pre & $3.22(0.71)$ & $3.46(0.42)$ \\
\hline Post & $3.88(0.44)$ & $3.65(0.57)$ \\
\hline \multicolumn{3}{|l|}{ Barriers to Healthy Eating ${ }^{a}$} \\
\hline Pre & $4.24(1.68)$ & $4.06(1.34)$ \\
\hline Post & $3.00(1.70)$ & $4.19(1.97)$ \\
\hline \multicolumn{3}{|c|}{ Physical Activity Self-Efficacy $(\alpha=.75)$} \\
\hline Pre & $18.44(4.46)$ & $19.25(3.76)$ \\
\hline Post & $18.76(3.85)$ & $18.47(3.51)$ \\
\hline \multicolumn{3}{|c|}{ Exercise Thoughts and Barriers $(\alpha=.79)$} \\
\hline Pre & $53.24(6.86)$ & $43.69(8.52)$ \\
\hline Post & $48.88(8.64)$ & $48.47(8.63)$ \\
\hline \multicolumn{3}{|l|}{ Body Weight Satisfaction } \\
\hline Pre & $1.71(0.85)$ & $3.12(1.36)$ \\
\hline Post & $2.12(1.05)$ & $3.06(1.44)$ \\
\hline \multicolumn{3}{|c|}{ Negative Thoughts about Food/Body } \\
\hline Pre & $3.69(0.70)$ & $3.13(1.09)$ \\
\hline Post & $3.24(1.15)$ & $3.19(1.05)$ \\
\hline
\end{tabular}

Note. IES = Intuitive Eating Scale

${ }^{a}$ ANCOVA significant at $p \leq .01$, baseline scores for each scale were used as covariates for respective analyses. 
Keeler, L.A., Clifford, D.E., August, B., Kowalski, P., Morris, M.N./ Californian Journal of Health Promotion 2013, Volume XX, Issue XX,

Table 3

Stages of Change for Exercise at Baseline and Post Intervention for Intervention and Control Groups

\begin{tabular}{lllll}
\hline & Intervention $\%(\mathrm{n})$ & \multicolumn{3}{l}{ Control \% (n) } \\
\hline & Pre-test & Post-test & Pre-test & Post-test \\
\hline PC & - & - & - & - \\
CO & $17.6 \%(3)$ & - & - & $6.7 \%(1)$ \\
PR & $76.5 \%(13)$ & $47.1 \%(8)$ & $43.8 \%(7)$ & $46.7 \%(7)$ \\
AX & - & $41.2 \%(7)$ & $18.8 \%(3)$ & $20.0 \%(3)$ \\
MN & $5.9 \%(1)$ & $11.8 \%(2)$ & $37.5 \%(6)$ & $26.7 \%(4)$ \\
\hline
\end{tabular}

Note. $\mathrm{PC}=$ precontemplation, $\mathrm{CO}=$ contemplation, $\mathrm{PR}=$ preparation, $\mathrm{AX}=$ action, $\mathrm{MN}=$ maintenance

subscale of eating for physical rather than emotional reasons. This difference in subscale scores was large as indicated by the calculated partial eta squared (Cohen, 1988), with group status accounting for $20 \%$ of the variance in scores. The change in scores for eating for physical rather than emotional reasons is encouraging, particularly since this scale measures tendency to eat to soothe or to cope with stress or boredom and almost two-thirds of the present sample reported emotional coping as a barrier to eating healthy. Tykla (2006) outlined how emotional overeating tends to be more of a concern for those who are attempting to restrict caloric intake. Many of the individuals in the intervention group stated weight loss motivation at onset and had previously attempted restrictive diets, thus, may have been more susceptible to emotional eating. Empowering young adults with awareness and techniques to avoid this negative eating pattern is important and the current intervention appears to have led to a decrease in self-reported emotional eating.

Lack of time and lack of money have been the most commonly cited barriers by college students (Clifford \& Keeler, 2009; Silliman et al., 2004). This is the first known study that measured the effects of an intervention on perceived healthy eating barriers in a university population. Following the intervention, the groups did differ in the total number of reported barriers to eating healthy. After adjusting for baseline barriers to eating healthy, a large effect was found (Cohen, 1988) between the FitU and control groups with $21 \%$ of the variance in post- test scores explained by the intervention. Consequently, it appears that a peer-led, tailored intervention may reduce college females' perceived barriers to eating healthy.

Exercise habits as measured by a stage of change scale improved substantially compared to the control group over the course of the intervention. Overall, 65\% of FitU participants progressed along the stages of change scale (i.e. moved from preparation to action) compared to only $20 \%$ of the control group. This increase in physical activity is consistent with previously tailored interventions (Marcus, Banspach et al., 1992; Marcus et al., 1998). Further, in the present study, the remaining intervention cohort (35\%) reported maintaining stage of change with none reporting relapse, whereas $40 \%$ of the control group maintained their stage and $40 \%$ relapsed to a previous stage. This is consistent with others who have found fewer exercise program dropout rates (i.e. relapse) when individuals received exercise adherence counseling (Zizzi, Parker, \& Blom, 2004) and those who have found greater rates of physical activity maintenance after a nutrition and exercise intervention (Hivert, Langlois, Bérard, Cuerrier \& Carpentier, 2007). Although exercise thoughts and barriers did not differ between groups in the ANCOVA analysis, this is likely explained by the non-randomized sampling. At the onset, FitU participants reported greater number of barriers and thoughts to exercise than the control group and significantly decreased these barriers at the conclusion of the study (see Table 2). Overall, the brief intervention appears 
to have positively influenced certain exercise behaviors and beliefs.

There were no significant differences in body weight satisfaction or negative thoughts about food/body following the intervention. However, it was found with post hoc analysis that FitU participants did have lower satisfaction scores than the control group at both baseline and at conclusion (see Table 2). These trends support the use of weight-neutral approaches, such as HAES, to minimize harm to body image as described in the current intervention and the need to address body image concerns when training peer-mentors (Zabinski, Calfas, Gehrman, Wilfley, \& Sallis, 2001).

\section{Figure 1}

Intervention

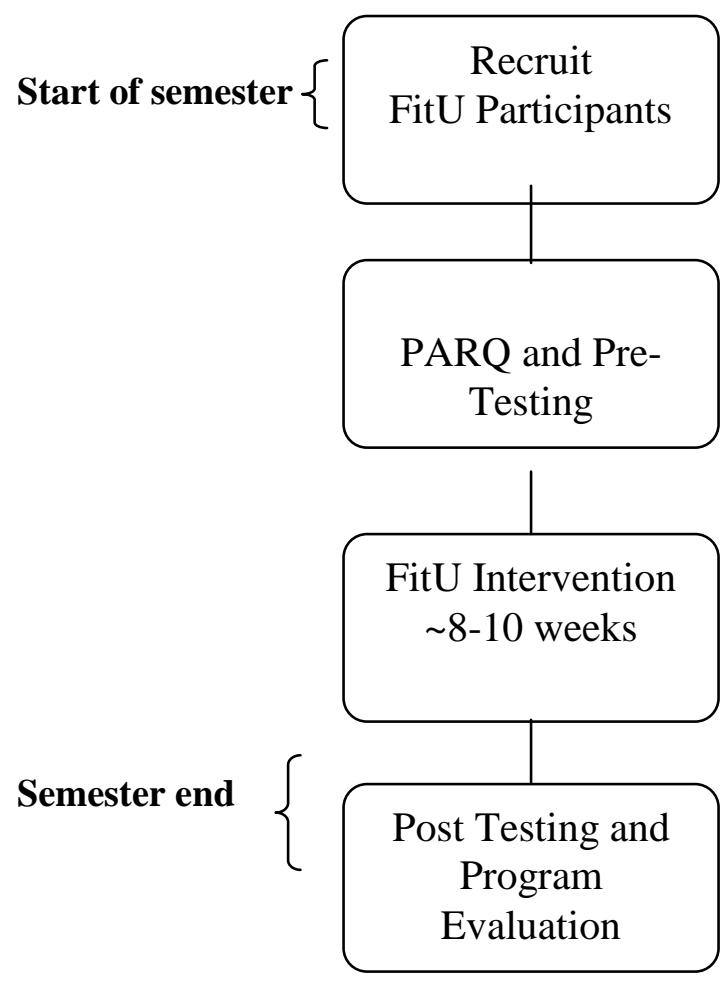

\section{Limitations}

Although this pilot program led to positive changes among certain nutrition and exercise variables, follow-up data is not currently available (a second long-term evaluation study is underway at the time of this article submission), and long-term changes cannot be assumed. Indeed, in a previous study reported physical activity gains relapsed at two-year follow-up (Calfas et al., 2000); however, this intervention differed in structure than the current study. It is also unclear if the attitudes towards eating or body weight satisfaction will be sustained,

\section{Control}

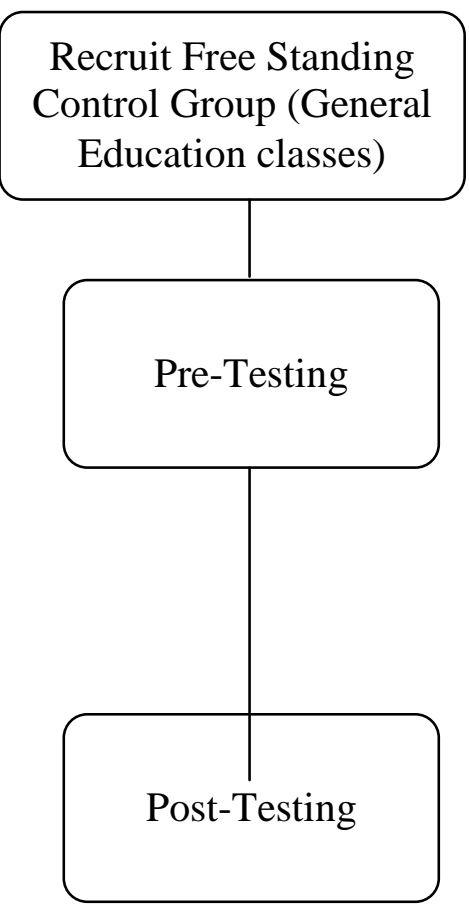

however, participants enrolled in a longer HAES intervention did maintain positive changes in dietary attitudes related to restriction and disinhibition, as well as improved body image at two-year follow-up (Bacon et al., 2005). The small sample size and brief structure of the present intervention may explain the absence of improvements in physical activity self-efficacy, total and other intuitive eating scores and body image items. Appointments were tailored to the individual, which was a strength of the intervention; however, inevitably the individual focus within a time constraint does decrease the 
opportunity to cover all concepts related to healthy nutrition and exercise habits. A larger scale, long-term follow-up design that includes a larger and more diverse sample is recommended for future investigations.

The differences in the intervention and the control groups were also a potential limitation to the current design. The control group was meant to be a simple observation of college students over the course of a semester; however, it is possible that control group members sought interventions on their own, which was not assessed in the follow-up survey. Since the intervention group was a self-selected group of individuals, there could also have been underlying differences in other important differences in the two groups that were not assessed. The intention of the use of the ANCOVA statistic was to control for baseline differences to minimize this limitation.

\section{Implications for Research and Practice}

Overall, the intervention group did report satisfaction with the FitU program and the majority reported improvements to dietary and exercise patterns/thoughts. The variables measured in the present study may not be a comprehensive list of the patterns/thoughts that were affected by the intervention. A mixedmethods design (quantitative/qualitative) may be suited for alternate programming to assess the scope of the impact it may have on attitudes and behaviors.

Given that college students' diet and physical activity patterns are typically poor, and that lifestyle behaviors adopted during the college years are likely to track into later adulthood, effective interventions promoting behavior change to reduce the risk of poor nutrition and inactivity are needed. A peer-led, HAES, multibehavior approach appears promising given the present results and the high level of participant satisfaction with the program. Further, programs that include peer mentors who receive college credit for their work ensures low cost sustainability of the program. Due to some challenges experienced with multiple and busy schedules of student mentors, it is recommended that a separate office manager intern or employee be in place to handle client screening, initial scheduling and added assistance in follow-up with clients when needed. Additional research is needed to further evaluate HAES programming for college students and to measure long-term effects with a larger and more diverse student population.

\section{References}

Ackard, D. M, Croll, J. K., \& Kearney-Cooke, A. (2002). Dieting frequency among college females: Association with disordered eating, body image, and related psychological problems. Journal of Psychosomatic Research, 52, 129-136.

American College Health Association. (2011). American College Health Association - National college health assessment II: Reference group executive summary Fall 2010. Linthicum, MD: American College Health Association.

Bacon, L., \& Aphramor, L. (2011). Weight science: Evaluating the evidence for a paradigm shift. Nutrition Journal, 10, 69.

Bacon, L., Keim, N. L., Van Loan, M. D., Derrictoe, M., Gale, B., Kazaks, A., \& Stern, J. S. (2002). Evaluating a 'non-diet' wellness intervention for improvement of metabolic fitness, psychological well-being and eating and activity behaviors. International Journal of Obesity, 26, 854-865.

Bacon, L., Stern, J. S., Van Loan, M. D., \& Keim, N. L. (2005). Size acceptance and intuitive eating improve health for obese, female chronic dieters. Journal of American Dietetic Association, 105, 929-936.

Burke, L. E., Dunbar-Jacob, J., Orchard, T. J., \& Sereika, S. M. (2005). Improving adherence to a cholesterol-lowering diet: A behavioral intervention study. Patient Education and Counseling, $57,134-142$. 
Keeler, L.A., Clifford, D.E., August, B., Kowalski, P., Morris, M.N./ Californian Journal of Health Promotion 2013, Volume XX, Issue XX,

Calfas, K. J., Sallis, J. F., Nichols, J. F., Sarkin, J. A., Johnson, M. F., Caparosa, S., \& ... Alcaraz, J. E. (2000). Project GRAD: Two-year outcomes of a randomized controlled physical activity intervention among young adults. American Journal of Preventive Medicine, 18(1), 28-37.

Castro, C. M., Sallis, J. F., Hickmann, S. A., Lee, R. E., \& Chen, A. H. (1999). A prospective study of psychosocial correlates of physical activity for ethnic minority women. Psychology and Health, 14, 277-293.

Clifford, D., \& Keeler, L. A. (2009, October). The relationship of perceived barriers to healthy eating and eating competence on a college campus. Paper presented at the American Dietetic Association Food and Nutrition Conference and Expo, Denver, CO.

Cluskey, M. \& Grobe, D. (2009). College weight gain and behavior transitions: Male and female differences. Journal of the American Dietetic Association, 109, 325-329.

Cohen, J. (1988). Statistical power analysis for the behavioral sciences ( $2^{\text {nd }}$ ed.). Hillsdale. NJ: Erlbaum.

Dunn, A., L., Marcus, B. H., Kampert, J. B., Garcia, M E., Kohl, H. W., III, \& Blair, S. N. (1999).

Comparison of lifestyle and structured interventions to increase physical activity and cardiorespiratory fitness: A randomized trial. JAMA: Journal of the American Medical Association, 281, 327-334.

Elbel, R., Aldana, S., Bloswick, D., \& Lyon, J. L. (2003) A pilot study evaluating a peer led and professional led physical activity intervention with blue-collar employees. Work, 21, 199-210.

Elliot, D. L., Goldberg, L., Kuehl, K. S., Moe, E. L., Breger, R. K., \& Pickering, M. A. (2007). The PHLAME (promoting healthy lifestyles: alternative models' effects) firefighter study: Outcomes of two models of behavior change. Journal of Occupational and Environmental Medicine, 49, 204-213.

Ferrara, C. M. (2009). The college experience: Physical activity, nutrition, and implications for intervention and future research. Journal of Exercise Physiology Online, 12(1), 23-35.

Hivert, M. F., Langlois, M. F., Bérard, P., Cuerrier, J. P., \& Carpentier, A. C. (2007). Prevention of weight gain in young adults through a seminar-based intervention program. International Journal of Obesity, 31, 1262-1269.

Kahn, E. B., Ramsey, L. T., Brownson, R. C., Heath, G. W., Howze, E. H., Powell, K. E., \& ... Corso, P. (2002). The effectiveness of interventions to increase physical activity: A systematic review. American Journal of Preventive Medicine, 22(Suppl. 4), 73-106.

Keating, X. D., Guan, J., Pinero, J. C., \& Bridges, D. M. (2005). A meta-analysis of college students' physical activity behaviors. Journal of American College Health, 54(2), 116-125.

Kendzierski, D., \& Johnson, W. (1993). Excuses, excuses, excuses: A cognitive behavioral approach to exercise implementation. Journal of Sport \& Exercise Psychology, 15, 207-219.

Kunkel, M. E., Bell, L. B., \& Luccia, B. H. D. (2001). Peer nutrition education program to improve nutrition knowledge of female collegiate athletes. Journal of Nutrition Education, 33, 114-115.

Larson, N., Perry, C., Story, M., \& Neumark-Sztainer, D. (2006). Food preparation by young adults is association with better diet quality. Journal of the American Dietetic Association, 106, 20012007.

Lowry, R., Galuska, D. A., Fulton, J. E., Wechsler, H., Kann, L., \& Collins, J. (2000). Physical activity, food choice, and weight management goals and practices among U.S. college students. American Journal of Preventive Medicine, 18(1), 18-27.

Mann, T., Tomiyama, A., Westling, E., Lew, A., Samuels, B., \& Chatman, J. (2007). Medicare's search for effective obesity treatments: Diets are not the answer. American Psychologist, 62, 220-233.

Marcus, B. H., Banspach, S. W., Lefebvre, R. C., Rossi, J. S., Carleton, R. A., \& Abrams, D. B. (1992). Using the stages of change model to increase the adoption of physical activity among community participants. American Journal of Health Promotion, 6, 424-429.

Marcus, B. H., Emmons, K. M., Simkin-Silverman, L. R., Linnan, L. A., Taylor, E. R., Bock, B. C. \& Abrams, D. B. (1998). Evaluation of motivationally tailored vs. standard self-help physical activity interventions at the workplace. American Journal of Health Promotion, 12, 246-253. 
Keeler, L.A., Clifford, D.E., August, B., Kowalski, P., Morris, M.N./ Californian Journal of Health Promotion 2013, Volume XX, Issue XX,

Marcus, B. \& Forsyth, L. (2009). Motivating people to be physically active ( $2^{\text {nd }}$ ed.). Champaign, IL: Human Kinetics.

Marcus, B. H., Rossi, J. S., Selby, V. C., Niaura, R. S., \& Abrams, D. B. (1992). The stages and processes of exercise adoption and maintenance in a worksite sample. Health Psychology, 11, 386-395.

Marcus, B. H., Selby, V. C., Niaura, R. S., \& Rossi, J. S. (1992). Self-efficacy and the stages of exercise behavior change. Research Quarterly for Exercise \& Sport, 63(1), 60-66.

Mellanby, A. R., Rees, J. B., \& Tripp, J. H. (2000). Peer-led and adult-led school health education: A critical review of available comparative research. Health Education Research, 15, 533-545.

Neumark-Sztainer, D., Wall, M., Guo, J., Story, M., Haines, J., \& Eisenberg, M. (2006). Obesity, disordered eating, and eating disorders in a longitudinal study of adolescents: How do dieters fare 5 years later? Journal of the American Dietetic Association, 106, 559-568.

Oppenheim, A. N. (1992). Questionnaire design, interviewing and attitude measurement. London: Pinter.

Perez-Escamilla, R., Hromi-Fiedler, A., Vega-Lopez, S., Bermudez-Millan, A., \& Segura-Perez, S. (2008). Impact of peer nutrition education on dietary behaviors and health outcomes among Latinos: A systematic literature review. Journal of Nutrition Education and Behavior, 40, 208225.

Prochaska, J. O., \& DiClemente, C. C. (1983). Stages and processes of change of smoking: Toward an integrative model of change. Journal of Consulting and Clinical Psychology, 51(3), 390-395.

Prochaska, J. O., DiClemente, C. C., Velicer, W. F., \& Rossi, J. S. (1993). Standardized, individualized, interactive, and personalized self-help programs for smoking cessation. Health Psychology, 12, $399-405$.

Proper, K. I., Hildenbrandt, V. H., Van der Beek, A. J., Twisk, J. W. R., Van Mechelen, W. V. (2003). Effect of individual counseling on physical activity fitness and health: A randomized controlled trial in a workplace. American Journal of Preventitive Medicine, 24(3), 218-226.

Provencher, V. V., Polivy, J. J., Wintre, M. G., Pratt, M. W., Pancer, S. M., Birnie-Lefcovitch, S. S., \& Adams, G. R. (2009). Who gains or who loses weight? Psychosocial factors among first-year university students. Physiology \& Behavior, 96, 135-141.

Robinson, J., Putnam, K., \& McKibbin, L. (2007). Health at every size: A compassionate, effective approach for helping individuals with weight-related concerns--Part II. American Association of Occupational Health Nurses Journal, 55, 185-192.

Sallis, J. F., Calfas, K. J., Nichols, J., Sarkin, J. A., Johnson, M. F., Caparosa, S., \& ... Alcaraz, J. (1999). Evaluation of a university course to promote physical activity: Project GRAD. Research Quarterly for Exercise and Sport, 70 (1), 1-10.

Silliman, K., Rosas-Fortier, K., \& Neyman, M. (2004). Survey of dietary and exercise habits and perceived barriers to following a healthy lifestyle in a college population. California Journal of Health Promotion, 2(2), 10-19.

Stevens, V. J., Glasgow, R. E., Toobert, D. J., Karanja, N., \& Smith, K. S. (2003). One-year results from a brief, computer-assisted intervention to decrease consumption of fat and increase consumption of fruits and vegetables. Preventive Medicine, 36, 594-600.

Story, M., Lytle, L. A., Birnbaum, A. S., \& Perry, C. L. (2002). Peer-led, school-based nutrition education for young adolescents: Feasibility and process evaluation of the TEENS study. Journal of School Health, 72, 121-127.

Thomas, S. L., Lewis, S., Hyde, J., Castle, D., \& Komesaroff, P. (2010). "The solution needs to be complex." Obese adults' attitudes about the effectiveness of individual and population based interventions for obesity. BMC Public Health, 10, 420.

Tylka, T. L. (2006). Development and psychometric evaluation of a measure of intuitive eating. Journal of Counseling Psychology, 53, 226-240.

Zabinski, M. F., Calfas, K. J., Gehrman, C. A., Wilfey, D. E., \& Sallis, J. F. (2001). Effects of a physical activity intervention on body image in university seniors: Project GRAD. Annals of Behavioral Medicine, 23(4), 247-252. 
Keeler, L.A., Clifford, D.E., August, B., Kowalski, P., Morris, M.N./ Californian Journal of Health Promotion 2013, Volume XX, Issue XX,

Page numbers $X X$

Zizzi, S. J., Parker, P. M., \& Blom, L. (2004). Evaluating the effectiveness of a screening and intervention program on clinic-based exercise adherence. Paper presented at the 2004 Annual Conference of the Association for the Advancement of Applied Sport Psychology. Minneapolis, MN.

$\underline{\text { Author Information }}$

*Linda A. Keeler, EdD, CC-AASP

Western Washington University

Department of Physical Education, Health and Recreation

Email: linda.keeler@wwu.edu

Phone: 360-650-3514

Fax: 360-650-7447

Dawn E. Clifford, PhD, RD

California State University, Chico

Department of Nutrition and Food Sciences

Buck August, MS, RD

California State University, Chico

Department of Nutrition and Food Sciences

Petra Kowalski, MA

California State University, Chico

Department of Kinesiology

Michelle Neyman Morris, PhD, RD

California State University, Chico

Department of Nutrition and Food Sciences

* corresponding author 